\title{
All in the name of work? Nonwork orientations as predictors of salary, career satisfaction, and life satisfaction
}

\author{
Andreas Hirschi ${ }^{\mathrm{a}, *}$, Anne Herrmann ${ }^{\mathrm{b}}$, Noemi Nagy ${ }^{\mathrm{a}}$, Daniel Spurk ${ }^{\mathrm{a}}$ \\ a University of Bern, Institute for Psychology, Fabrikstrasse 8, CH-3012 Bern, Switzerland \\ b University of Applied Sciences Northwestern Switzerland, Riggenbachstrasse 16, CH-4600 Olten, Switzerland
}

\section{A R T I C L E I N F O}

\section{Article history:}

Received 20 April 2016

Received in revised form 15 July 2016

Accepted 25 July 2016

Available online 26 July 2016

\section{Keywords:}

Nonwork orientations

Work-home perspective

Career success

Life satisfaction

\begin{abstract}
A B S T R A C T
Career development increasingly demands a successful integration of work and nonwork domains. Based on work-nonwork conflict and enrichment theories, this study explored the relationship between nonwork orientations (i.e., family, personal life, and community) and both objective (i.e., salary) and subjective (i.e., career satisfaction) career success and life satisfaction over a period of six months among a sample of 548 employees from Germany. The results generally support the enrichment perspective. Family orientation showed a positive relationship with career satisfaction. All three nonwork orientations, especially family orientation, were positively related to life satisfaction. We also explored gender and age effects but found no differences in nonwork orientations between young employees aged 25-34 years and older workers aged 50-59 years. Men showed lower levels of personal life orientation than women, but no differences in family or community orientation based on gender were found. We also did not observe gender $\mathrm{x}$ age interaction effects. We discuss the study's implications for a whole-life perspective on career development, career success, and well-being.
\end{abstract}

(c) 2016 Published by Elsevier Inc.

\section{Introduction}

The increase in flexible work arrangements, the raising number of women in the workforce, and generational shifts in work values have led to increased interrelatedness between the work and nonwork domains (Greenhaus \& Kossek, 2014). As a result, most people's career development is strongly influenced by nonwork roles as many work decisions, such as whether to enter or exit a job, whether to pursue self-employment, or whether to expatriate, are affected by factors outside the work domain (Powell \& Greenhaus, 2010). However, existing research has largely focused on work-family issues and has not sufficiently accounted for the potentially profound effects of other nonwork domains besides the family domain on individuals' careers (Hall, Kossek, Briscoe, Pichler, \& Lee, 2013). Moreover, while investigations on multiple role commitment have generally shown positive effects on well-being (Barnett, 2008), research has largely ignored, or produced contradictory results, regarding how consideration of diverse nonwork roles affects career outcomes (Graves, Ohlott, \& Ruderman, 2007; Ruderman, Ohlott, Panzer, \& King, 2002; Weer, Greenhaus, \& Linnehan, 2010). To understand the nature of contemporary careers, it is vital to obtain a better understanding of how individuals consider nonwork roles when managing their careers and of what such a consideration implies for career outcomes (Greenhaus \& Kossek, 2014).

In an attempt to deepened the understanding of how career development is linked with nonwork roles, Hall et al. (2013) proposed that research must consider individual differences in people's orientations toward various life roles, including-but not

\footnotetext{
* Corresponding author.

E-mail addresses: andreas.hirschi@psy.unibe.ch (A. Hirschi), anne.herrmann@fhnw.ch (A. Herrmann), noemi.nagy@psy.unibe.ch (N. Nagy), daniel.spurk@psy.unibe.ch (D.Spurk).
} 
limited to-family roles. Such nonwork orientations (NWOs) refer to the degree of concern that one has for other roles relative to one's career (Hall et al., 2013). However, the extent to which these NWOs are related to career and well-being outcomes remains unexamined. This gap is important to address because a work-nonwork perspective on careers urges researchers to examine whether employees who take nonwork considerations into account when managing their careers experience greater satisfaction in their careers and their lives (Greenhaus \& Kossek, 2014).

Drawing on theories of work-nonwork conflict and enrichment, we addressed this issue and investigated the extent to which NWOs are related to objective (i.e., salary) and subjective (i.e., career satisfaction) indicators of career success. Moreover, we examined how NWOs are related to life satisfaction. In addition, we considered gender and age as potentially important factor to explain individual differences in NWOs and their functioning. Addressing these issues makes several contributions to the literature. First, it significantly advances our understanding of how the endorsement of NWOs is related to career success and wellbeing outcomes. Second, it enriches our understanding of individual differences in the endorsement of NWOs for different gender and age groups. Third, it provides novel insights into whether NWOs have differential effects on career success and well-being for different types of employees. As such, our paper makes a contribution to the more general understanding of contemporary forms of work and careers that are at the intersection of the work and nonwork spheres of life (Greenhaus \& Kossek, 2014).

\subsection{NWOs as a new construct linking nonwork roles and career outcomes}

Hall et al. (2013) introduced the concept of NWOs as a reaction to the nonspecific treatment of diverse nonwork related domains (e.g., family, self, community, or leisure) in past research. The authors conceptualized NWOs in contrast to a solely careerfocused orientation and to assess concerns for nonwork roles relative to career. Based on a literature review and qualitative case studies, three different types of NWOs were proposed. A family orientation was defined as "the degree to which one attaches importance to family needs relative to one's career role" (Hall et al., 2013, p. 541). An orientation toward personal life was defined as "a focus on the time for oneself to pursue personal interests (e.g., hobbies, learning, the arts, and exercise), whereas at the same time engaging in a career" (Hall et al., 2013, p. 541). Finally, a community service orientation was described as a "high concern for being able to engage in service to the community where one lives at the same time one is pursuing a career" (Hall et al., 2013, p. 541). Hall et al. (2013) then developed an NWO scale that captures these three dimensions. The three dimensions were distinct but moderately interrelated. Furthermore, the validation study showed positive relationships of the three NWOs with a protean career orientation, a self-directed orientation and a values-driven orientation toward career management.

Although empirical research on NWOs specifically is only emerging, many studies have investigated consequences of the closely related constructs of role centrality, role commitment, and role involvement, mostly regarding the job and family roles. Role centrality has been defined as the relative value the individual places on a role identity and the time and energy invested in a role (Kossek, Ruderman, Braddy, \& Hannum, 2012). Role commitment can be defined as the extent to which somebody is willing to commit personal resources to assure success in the role or to develop the role (Amatea, Cross, Clark, \& Bobby, 1986). Role involvement is defined as the degree to which the individual identifies with a role and the importance of the role in one's life (Brown, 1996). Although these concepts show nuanced differences, they can be regarded as specific indictors of a more general role commitment construct (Cooper-Hakim \& Viswesvaran, 2005).

Meta-analyses investigating job and family involvement have shown that people with higher job involvement generally report more work-family conflict while smaller or nonsignificant effects have been observed for family involvement (Byron, 2005; Michel, Kotrba, Mitchelson, Clark, \& Baltes, 2011). However, other meta-analyses suggest that a higher involvement in the work role is generally positively related to job satisfaction and performance (Brown, 1996; Cooper-Hakim \& Viswesvaran, 2005; Lee, Carswell, \& Allen, 2000). Moreover, meta-analysis on career success showed that job involvement, work centrality, and occupational commitment are positively related to salary ( $\mathrm{Ng}$, Eby, Sorensen, \& Feldman, 2005; Ng \& Feldman, 2014a), promotions (Ng et al., 2005) and subjective career success (Ng \& Feldman, 2014b; Ng et al., 2005). However, these studies did not examine effects of involvement in other life roles relative to the involvement in the work role.

Research investigating effects of involvement in multiple roles generally supported the expansionist hypotheses, that engagement in multiple roles is generally positively related to increased well-being and resilience (Barnett, 2008). These effects are likely to occur because multiple roles can buffer negative effects of one role by success and satisfaction in another role, increase selfcomplexity, and provide multiple opportunities for success experiences and a sense of confidence in various roles (Barnett, 2008). However, while several studies reported positive effects of involvement in multiple roles on general well-being, as well as on job and family satisfaction (e.g., Barnett \& Hyde, 2001; Grawitch, Maloney, Barber, \& Mooshegian, 2013; Kirchmeyer, 1992; Ruderman et al., 2002), few studies have investigated how commitment to multiple roles is related to career success outcomes. Moreover, the few existing studies provided inconclusive results. Ruderman et al. (2002) found that among female managers, commitment to multiple roles was positively related to an increased sense of effectiveness in the management role in addition to higher life satisfaction, self-esteem, and self-acceptance. In a study among male and female managers Graves et al. (2007) found that family role commitment was not related to family-to-work interference but had a positive effect on career satisfaction and performance, partially mediated by family-to-work enhancement. However, in a study of female legal secretaries, Weer et al. (2010) found that an extensive commitment to nonwork roles was overall negatively related with job performance because of negative effects of expended emotional energy on nonwork roles that surpassed the more minor positive indirect effects through resources acquired from nonwork roles. Hence, there is a need to better understand how the involvement in multiple life roles is related to career success outcomes. 
NWOs can provide a unique lens on this issue. Although NWOs are conceptually related to involvement in nonwork roles, they more specifically tap into concerns for nonwork roles relative to an individual's career. Hence, NWOs are not the same as importance or salience of work or nonwork roles and do not directly assess the extent to which career and work are central life interests (Hall et al., 2013). Although Hall et al. (2013) have not provided a more detailed theoretical elaboration on the connection between NWOs and role commitment, we would conceptualize NWOs as a potential outcome of high commitment to nonwork roles. Hence, in contrast to more general role commitment, NWOs are more context-specific because they assess the consideration of a nonwork role relative to one's career. Based on considerations of fidelity between predictor and outcome variables, NWOs thus seem especially suited to investigate how consideration of nonwork roles are related to career outcomes. As such, NWOs seem particularly useful to increase the still underdeveloped understanding of how work-life issues are related to career management and career outcomes (Greenhaus \& Kossek, 2014).

\subsection{NWO from a work-nonwork conflict and enrichment perspective}

Because NWOs represent considerations for nonwork roles relative to one's career that are likely to result from higher commitment to these nonwork roles, we herein draw on two of the most prominent perspectives in the work-family literature to conceptualize possible consequences of NWOs: the conflict and enrichment perspectives linking work and nonwork roles. The conflict perspective is based on role theory (Katz \& Kahn, 1978), which proposes that every role (e.g., work, family, community, leisure) comes with a set of demands related to this role. Work-nonwork conflict is assumed to emerge when demands from work and nonwork roles are mutually incompatible such that meeting demands in one role make it difficult to meet demands in the other role (Greenhaus \& Beutell, 1985). In addition, demands in the work-family literature are also often conceptualized based on the conservation of resources theory (Hobfoll, 1989), where role demands are considered stressors that deplete personal resources because they require sustained physical and/or mental effort to meet (Ten Brummelhuis \& Bakker, 2012). Conflicts between roles are specifically assumed to occur because of the time devoted to a role that takes time away from meeting demands in other roles, the strain required to meet role demands that leads to a lack of energy to meet demands in other roles, or behaviors required in one role that are incompatible with behaviors required in other roles (Greenhaus \& Beutell, 1985).

In contrast, the enrichment perspective suggests that work and nonwork roles do not necessarily lead to conflict; rather, they can also be mutually enriching (Greenhaus \& Powell, 2006). According to this perspective, being simultaneously engaged in multiple roles can enhance well-being and performance across roles because of positive spillover. Specifically, enrichment can occur through an instrumental path because resources (e.g., skills, social capital, self-efficacy) acquired in one role can be used to meet demands in another role. In addition, through an affective path of enrichment, positive affect created in one role can improve performance in other roles (Greenhaus \& Powell, 2006). In more general terms, resources accumulated in one role can enhance personal resources, which can then be used to meet demands in other roles (Ten Brummelhuis \& Bakker, 2012). Enrichment and conflict are presumed to be independent constructs (Greenhaus \& Powell, 2006), and research suggests that they can occur simultaneously for two given roles (Rothbard, 2001).

The conflict and enrichment perspectives can provide a useful theoretical foundation to conceptualize the likely outcomes of NWOs. On a general level, because we conceptualize NWOs as a potential outcome of high role commitment, we can assume that people with stronger NWOs show more commitment to nonwork roles compared with people with weaker NWOs. Role theory (Katz \& Kahn, 1978) proposes that people invest resources (e.g., energy, time, and money) in different life roles according to their subjective salience and importance. It is therefore likely that people with strong NWOs invest more resources in nonwork roles than people with weaker NWOs. High NWOs do not automatically mean low work role importance, as people can be equally committed to several life roles (Hall et al., 2013). However, from a conflict perspective, heavy investment of resources in nonwork roles would lead to a depletion of resources, which would diminish their ability to meet the demands of their work role due to a lack of time, energy, or incompatible behaviors (Greenhaus \& Beutell, 1985). By contrast, the enrichment perspective suggests that holding NWOs and being actively engaged in nonwork roles increases the chance of experiencing positive affect in these roles and of acquiring resources in nonwork roles that increase performance and the capacity to meet demands in the work role. Because both perspectives are theoretically feasible and because there is no prior empirical research on this issue in relation to NWOs, we develop theoretical arguments and propose hypotheses from the perspectives of both conflict and enrichment. Our study then tests which of the two perspectives receives more support.

In the present study, we conceptualize NWOs as predictors of career success and well-being. This is in line with theoretical reasoning in the work-family (Byron, 2005; Michel et al., 2011) as well as career success literature (Ng \& Feldman, 2014a, 2014b) that treat role involvement as an antecedent to experienced enrichment and conflict between roles and subsequent well-being, performance, and career success outcomes.

\subsection{NWOs and career success}

A study about how NWOs relate to career success is crucial because of an increased intersection of the work and nonwork spheres of life that may affect career success (Greenhaus \& Kossek, 2014). Career success can be defined as "the positive psychological or work-related criteria or achievements one accumulates as a result of work experiences" (Seibert, Crant, \& Kraimer, 1999, p. 417). Objective career success can be externally verified by variables such as salary or promotions (e.g., $\mathrm{Ng}$ et al., 2005). However, salary is the most frequently used indicator of objective career success because it can be applied to all forms of paid work. Subjective career success, in contrast, is the self-evaluation of satisfaction with career progress or other valued outcomes by an 
individual (Ng \& Feldman, 2014b). By simultaneously investigating objective and subjective career success, this study provides insights into whether NWOs are differentially related to different career success dimensions.

Regarding objective career success, the conflict perspective would suggest that because people with strong NWO invest more resources in nonwork roles, they have fewer resources available to invest in the advancement of their careers. Research suggests that high investment in work is beneficial for objective career success because different facets of work commitment, such as job involvement, occupational commitment, or work centrality, are all positively related to salary (Brown, 1996; Lee et al., 2000; Ng \& Feldman, 2014a; Ng et al., 2005). This can be explained in the way that work commitment can be considered a form of human capital that can enhance career attainment ( $\mathrm{Ng}$ et al., 2005). Because of resource depletion in nonwork roles, people with high NWO might exert less time, energy, and persistence to obtain objective career outcomes, such as salary. Moreover, work performance might suffer owing to minimized time and energy that could be more exclusively devoted to the work role. As a result, people with high NWO might be less likely to outperform their peers and obtain favorable career opportunities. Based on these considerations, the conflict perspective leads to the following hypothesis $(\mathrm{H})$ :

H1a. Nonwork orientations are negatively related to objective career success (i.e., salary).

From the enrichment perspective, because of their increased involvement in nonwork roles, people with strong NWO would increase the chance that they build important resources in nonwork aspects, such as new skills and perspectives, and psychological resources, such as self-esteem, health, social support, and networks (Greenhaus \& Powell, 2006). These resources could then be used to meet challenges at work, to increase job performance, and ultimately to gain more career advancement. Meta-analyses have confirmed that skills, self-esteem, networks, and social support represent human and social capital that is positively related to salary attainment (Ng \& Feldman, 2014a; Ng et al., 2005). In addition, active engagement in nonwork roles could increase positive affect that could then spillover into the work role and increase job performance (Greenhaus \& Powell, 2006). Meta-analyses have supported this view because positive trait affectivity is positively related to salary ( $\mathrm{Ng}$ \& Feldman, 2014a), possibly because positive affectivity is related to higher job performance (Kaplan, Bradley, Luchman, \& Haynes, 2009). Based on the enrichment perspective, we thus propose the following hypothesis:

\section{H1b. Nonwork orientations are positively related to objective career success (i.e., salary).}

Concerning the issue of how NWO might be related to subjective career success, the conflict perspective would suggest that owing to a depletion of resources in nonwork roles, people would be less able to achieve personally valued career objectives and thus would experience less career satisfaction. This view is supported by meta-analytic research that has shown that occupational commitment (Lee et al., 2000), job involvement (Brown, 1996), and organizational commitment (Meyer, Stanley, Herscovitch, \& Topolnytsky, 2002) are all positively related to overall job satisfaction and to an aggregate of different indicators of subjective career success ( $\mathrm{Ng} \&$ Feldman, 2014b). This result may occur because stronger work commitment leads to more invested resources in the working role that, in turn, favors the attainment of subjectively valued career outcomes (e.g., recognition, challenging work, influence) (Shockley, Ureksoy, Rodopman, Poteat, \& Dullaghan, 2015). Accordingly, to the extent that NWO leads to a depletion of resources that could alternatively be invested in the work role, NWOs might be negatively related to career satisfaction. Based on the conflict perspective, we thus propose the following hypothesis:

H2a. Nonwork orientations are negatively related to career satisfaction.

The enrichment perspective, in contrast, would imply that the resources and positive affect attained in nonwork roles help to achieve personally valued goals at work and thereby increase career satisfaction. Moreover, because we can presume that high NWO indicate a high investment of resources in nonwork roles, we can expect that people with high NWO would be more likely to achieve their nonwork goals. Based on the assumption that people increasingly take a whole-life perspective when evaluating their career (DiRenzo, Greenhaus, \& Weer, 2015; Greenhaus \& Kossek, 2014), the extent to which individuals' work fits into their whole life and to extent to which one has been able to achieve important goals outside the work domain constitute also a core component when people evaluate their career satisfaction (Shockley et al., 2015). Based on the enrichment perspective, we propose the following hypothesis:

H2b. Nonwork orientations are positively related to career satisfaction.

\subsection{NWO and life satisfaction}

The whole-life perspective on careers (Greenhaus \& Kossek, 2014) suggests that career development must be understood in relation to various life domains, including the relation of work and nonwork outcomes. Accordingly, this study goes beyond exploring the relationship of NWO and career outcomes and examines the link between NWO and general well-being, specifically life satisfaction.

From a conflict perspective, people with strong NWO might suffer from resource depletion because of their investment in nonwork roles that would impair their capacities to meet their job demands. This in turn might reduce positive work experiences (e.g., job satisfaction) and performance that could result in a negative spillover to life satisfaction. In support of this conjecture, research has established that various work outcomes (including job performance and satisfaction) are significantly related to 
life satisfaction (Erdogan, Bauer, Truxillo, \& Mansfield, 2012). In addition, people with high NWO might face more work-nonwork conflict because they attempt to meet demands in various life roles and thus are constantly confronted with the challenge of meeting various demands with limited resources. This turn would likely negatively affect their life satisfaction, as meta-analytic research has shown that experienced work-family conflict is related to a range of negative psychological and physical outcomes, including reduced life satisfaction (Allen, Herst, Bruck, \& Sutton, 2000). From the conflict perspective, we thus propose the following hypothesis:

H3a. Nonwork orientations are negatively related to life satisfaction.

The enrichment perspective suggests that NWOs are related to increased well-being and higher life satisfaction. A core assumption of the work-family enrichment perspective (Greenhaus \& Powell, 2006) is that simultaneous engagement in multiple roles can have several positive consequences; thus, it should increase overall well-being. First, work and nonwork experiences can have additive effects on well-being because satisfaction obtained in one area (e.g., personal leisure) can add to the overall well-being of a person and affect satisfaction obtained in another area (e.g., work). Second, different roles can buffer distress experienced in other roles. For example, satisfaction in the family role can buffer negative effects from distress at work. Finally, simultaneous engagement in different roles can build resources in each domain in terms of psychological resources (e.g., selfesteem) and social capital resources (e.g., social support) that can each uniquely contribute to a person's overall well-being (Greenhaus \& Powell, 2006). Based on the enrichment perspective, we thus propose the following hypothesis:

H3b. Nonwork orientations are positively related to life satisfaction.

\subsection{Exploring gender and age effects in NWOs}

Apart from investigating the relationship of NWOs with career success and well-being, we also wanted to provide more insight concerning individual differences in the endorsement of NWOs. Given the increase of women (Toossi, 2012) and older workers (van der Heijden, Schalk, \& van Veldhoven, 2008) in today's workforce, gender and age are two critical variables in understanding contemporary career development, and both might be meaningfully related to NWOs.

It is well-established that gender is a critical variable to understand work-family linkages because women traditionally take on the majority of care work in a family (Greenhaus \& Kossek, 2014). However, the relation between gender and different NWOs remains unexplored. Research has usually found that, due to traditional gender socialization, women have lower work centrality and higher family centrality compared with men (Greenhaus \& Kossek, 2014). Women generally place less importance on objective success in comparison to subjective success and focus more on family roles compared to men (Greer \& Egan, 2012). However, recent research does not always replicate these results and found no gender differences concerning work centrality (Sharabi, 2015). A meta-analysis also found no gender differences in occupational commitment (Lee et al., 2000). Finally, both roles, work and family, can be co-activated at the same time, meaning that high identification with the family role does not rule out similarly high identification with one's work role (Powell \& Greenhaus, 2010). Hence, existing research that is closely linked to the NWO concept is inconclusive whether men and women can be expected to show different levels of concern for nonwork roles relative to their career. We therefore do not propose a specific hypothesis but aim to address the following research question (RQ):

\section{RQ 1. Do men and women hold different levels of NWOs?}

In contrast to gender issues, the work-family literature has largely ignored age effects even though nonwork demands vary considerably over the life course, for example regarding education, child care, elderly care, or retirement planning (Allen \& Shockley, 2012). Moreover, due to demographic changes in many countries, a better understanding of career development of older workers is a key challenge for researchers, organizations, and societies (Wang, Olson, \& Shultz, 2013). Existing studies on age differences in importance of work and nonwork roles reported contradictory findings. Some theoretical arguments and empirical findings appear to suggest that NWOs are stronger among young than among old employees. Generational researchers state that the current economic and cultural context has led to an increased valuing of nonwork roles. This is reflected in generational differences in work values (Twenge, Campbell, Hoffman, \& Lance, 2010), specifically the finding that the youngest generation in the workforce values nonwork areas more than do older generations (Lyons \& Kuron, 2014). Another perspective stems from socio-emotional selectivity theory (Carstensen, Isaacowitz, \& Charles, 1999). The theory states that because of a changing time perspective with age (from an unlimited time perspective to a focus on time left), older workers generally value indicators of objective success and career advancement less than younger employees (Kooij, De Lange, Jansen, Kanfer, \& Dikkers, 2011). This might free-up time and energy resources not spent on work to focus on nonwork roles. Other studies found that work centrality decreases as retirement grows closer (Sharabi \& Harpaz, 2007), which speaks for the classic view of career stage theories, in which older workers are assumed to gradually disengage from work (Super, 1990). However, meta-analytic findings showed that older workers usually report higher job involvement (Brown, 1996), higher affective organizational commitment (Meyer et al., 2002) and higher occupational commitment (Lee et al., 2000) compared with younger workers. This suggests that work centrality remains high among older workers, which questions the assumption that NWOs would be lower among this group. We address these conflicting views with the following research question: 


\section{RQ 2. Do younger and older workers hold different levels of NWOs?}

Finally, we wanted to explore whether gender and/or age moderate the relationship between NWOs and the investigated career and well-being variables. Such an investigation sheds light on whether NWOs have differential effects for different employees and thereby provide a more nuanced understanding of the conditions under which NWOs might be positive or negative. Testing such moderation effects is meaningful because research often found only weak to moderate correlations between psychological factors (e.g., the related construct of job involvement) and career success ( $\mathrm{Ng}$ et al., 2005). This points to the importance of examining moderating factors such as gender and age regarding the link between psychological variables and career success outcomes (e.g., as done by Judge, Livingston, \& Hurst, 2012; Van der Heijden, de Lange, Demerouti, \& Van der Heijde, 2009).

RQ3. Is the relationship between NWOs and salary, career satisfaction, and life satisfaction moderated by gender and/or age?

In the present paper, we thus aimed to provide new insight into how gender and age, including their interaction, are related to NWOs and whether and how they might affect the relationship of NWOs with the examined outcomes. For this purpose, we sampled a balanced group of men and women. Moreover, we were specifically interested to compare young (i.e., 25 to 34 years) and old (i.e., 50 to 59 years) employees where age effects might be especially pronounced. By focusing on these two clearly distinct age groups, we were able to tap into very different career and life stages that are associated with very different work and nonwork demands. For example, younger employees are typically confronted with career challenges such as developing new skills, becoming socialized in one's job and profession, or managing a career while having young children. Conversely, older worker might more typically deal with issues such as preparation for retirement, maintaining a high level of productivity, or caring for older parents and grandchildren (Lent \& Brown, 2013). As such, our study provides meaningful insights into how gender and very different life and career stages are related to NWOs.

\section{Method}

\subsection{Sample and procedure}

Participants were recruited through an online-access panel research company. The respondents received incentives for successfully completed questionnaires, but there was an imposed maximum of two participations per week to ensure data quality. Research has established that participants in online research are at least as diverse as participants recruited by other means (Gosling, Vazire, Srivastava, \& John, 2004), and studies investigating career and work-family issues have successfully used online panels (e.g., DiRenzo et al., 2015; Masuda, McNall, Allen, \& Nicklin, 2012). A random sample of 880 participants corresponding to our selection criteria was drawn from a pool of over 320,000 German registrants. The recruited participants had to be employed for at least $16 \mathrm{~h}$ per week in private industry (excluding students, self-employed individuals, trainees, interns, and civil servants) and be in one of two age groups: between 25 and 34 years old or between 50 and 59 years old. We conducted extensive data quality checks concerning streamlining, carelessness, and speed. Based on these checks, 154 respondents were removed, resulting in a final sample at T1 of $N=726$. These participants were invited to participate in a follow-up survey six months later, with a response rate of $75 \%$ and $N=548$ as the final longitudinal sample that was used for testing the hypotheses. In all, $47 \%$ of the participants who participated at both measurement points were female, and 44\% were aged between 25 and 34 years.

Table 1

Descriptive statistics, reliability coefficients, and correlations $(N=548)$.

\begin{tabular}{|c|c|c|c|c|c|c|c|c|c|c|c|c|c|c|}
\hline Variables & $M$ & $S D$ & 2 & 3 & 4 & 5 & 6 & 7 & 8 & 9 & 10 & 11 & 12 & 13 \\
\hline 1. Having children & - & - & $0.46^{* *}$ & $-0.19^{* *}$ & $-0.11^{*}$ & $0.19^{* *}$ & -0.01 & $0.47^{* *}$ & $0.26^{* *}$ & 0.00 & $0.11^{* *}$ & 0.05 & 0.05 & 0.07 \\
\hline 2. Relationship status & - & - & - & -0.06 & -0.04 & $0.26^{* *}$ & $0.10^{*}$ & $0.27^{* *}$ & $0.34^{* *}$ & -0.03 & $0.14^{* *}$ & $0.16^{* *}$ & $0.12^{* *}$ & $0.19^{* *}$ \\
\hline 3. Contractual working hours & - & - & & - & $0.16^{* *}$ & -0.02 & $0.30^{* *}$ & $-0.27^{* *}$ & 0.00 & -0.07 & -0.03 & $0.36^{* *}$ & $0.09^{*}$ & $0.10^{*}$ \\
\hline 4. Educational level & - & - & & & - & -0.07 & 0.04 & $-0.16^{* *}$ & 0.08 & 0.02 & -0.05 & $0.25^{* *}$ & 0.05 & 0.08 \\
\hline 5. Organizational tenure & - & - & & & & - & $0.13^{* *}$ & $0.41^{* *}$ & $0.10^{*}$ & 0.00 & -0.01 & $0.27^{* *}$ & $0.13^{* *}$ & $0.11^{*}$ \\
\hline 6. Gender & - & - & & & & & - & 0.05 & -0.06 & $-0.13^{* *}$ & -0.01 & $0.35^{* *}$ & $0.09^{*}$ & $0.09^{*}$ \\
\hline 7. Age group & - & - & & & & & & - & -0.04 & 0.03 & 0.07 & $0.08^{*}$ & 0.03 & 0.01 \\
\hline 8. T1 family orientation & 3.32 & 1.06 & & & & & & & 0.94 & $0.37^{* *}$ & $0.30^{* *}$ & 0.05 & $0.18^{* *}$ & $0.27^{* *}$ \\
\hline 9. T1 personal life orientation & 3.94 & 0.79 & & & & & & & & 0.90 & $0.23^{* *}$ & -0.07 & 0.06 & $0.13^{* *}$ \\
\hline $\begin{array}{l}\text { 10. T1 community service } \\
\text { orientation }\end{array}$ & 2.94 & 0.87 & & & & & & & & & 0.84 & -0.07 & 0.06 & $0.09^{*}$ \\
\hline 11. T2 salary & - & - & & & & & & & & & & - & $0.29^{* *}$ & $0.25^{* *}$ \\
\hline 12. T2 career satisfaction & 3.34 & 0.91 & & & & & & & & & & & 0.92 & $0.62^{* *}$ \\
\hline 13. T2 satisfaction with life & 3.89 & 1.00 & & & & & & & & & & & & 0.83 \\
\hline
\end{tabular}

Note. The italic numbers on the diagonal are the Cronbach's alpha reliability coefficients (except for salary and controls). Having children: $0=$ no; $1=$ yes; relationship status: $0=$ single (single, widow, other relationship); $1=$ married or registered partnership; contractual working hours: free entry, hours per week; educational level: $0=$ only mandatory schooling; $1=$ vocational training; $2=$ university/college degree; organizational tenure: free entry, years spent at the current employer; gender: $0=$ female; $1=$ male; age group: $0=$ young (25-34); $1=$ old (50-59).

* $p<0.05$.

** $p<0.01$. 
Independent-samples $t$-test showed no differences in gender, age group, or the NWO variables between the longitudinal sample and those who participated only at T1.

NWOs were assessed at T1, and the career success and well-being measures were assessed at T2. This separation of measurement across time is useful to reduce common method bias (Podsakoff, MacKenzie, Lee, \& Podsakoff, 2003). The respondents came from a large variety of industry sectors and worked on average $36.5 \mathrm{~h}$ per week. The respondents' educational level was representative of the working population in Germany and ranged from no vocational training (4\%) to doctoral graduates (1\%). The majority of the participants had completed vocational training as their highest educational level (68\%), whereas $28 \%$ of the participants held a university degree. As is customary in Germany, race was not assessed, but almost all (98\%) of the participants were German citizens. Approximately half of the participants were parents (52\%), and $41 \%$ were married or registered in a partnership.

\subsection{Measures}

Unless otherwise indicated, the used scales were independently translated from their original English version into German by two of the authors. The final German items were formulated after reconciling differences in the translations. This procedure is often preferable to a back-translation procedure because it ensures the naturalness, connotation, and comprehensibility of the items (van de Vijver \& Leung, 1997). Means, standard deviations, intercorrelations, and Cronbach's alpha estimates for all scales are reported in Table 1.

\subsubsection{Nonwork orientations}

NWOs were assessed with 14 items on three scales (family, personal life, and community) by using the measure from Hall et al. (2013). The scale consists of five items for family (e.g., "My career decisions are made in terms of how they will affect my family."); five items for personal life (e.g., "Finding time for myself is important to my overall quality of life."); and four items for community service (e.g., "It is important to me to have a job that allows me the flexibility to be involved in my community."), and a 5-point Likert-type scale ranging from 1 (strongly disagree) to 5 (strongly agree) is used. Hall et al. (2013) found positive relationships between all NWO scales and a protean career orientation.

\subsubsection{Salary}

The participants were asked to indicate their gross salary in the last month in steps of 500 EUR (ranging from under 500 EUR to over 10,000 EUR per month). Gross salary varied from under 500 EUR (4\% of participants) to over 10,000 EUR per month (1\% of respondents), with a median salary of between 2000 and 2500 EUR per month. To obtain a more normal-shaped distribution, salary was transformed by using a natural log transformation.

\subsubsection{Career satisfaction}

Career satisfaction was assessed with the German translation (Abele \& Spurk, 2009) of the career satisfaction scale from Greenhaus, Parasuraman, and Wormley (1990). The scale consists of five statements (e.g., "Overall, I am satisfied with my job.") answered on a 5-point Likert-type scale ranging from 1 (strongly disagree) to 5 (strongly agree). Abele and Spurk (2009) provided support for the unidimensionality and construct validity of the scale in terms of significant correlations with salary and occupational status.

\subsubsection{Life satisfaction}

The German-language adaptation (Peterson, Ruch, Beermann, Park, \& Seligman, 2007) of the Satisfaction with Life Scale (SWLS) by Diener, Emmons, Larsen, and Griffin (1985) was applied. The scale consists of five statements (e.g., "In most ways, my life is close to my ideal.") answered on a 7-point Likert-type scale ranging from 1 (strongly disagree) to 7 (strongly agree). This scale is the most widely used measure of life satisfaction with significant relationships to other well-being indicators (Pavot \& Diener, 2008).

\section{Results}

\subsection{Preliminary analyses}

\subsubsection{Confirmatory factor analysis}

Prior to examining the relationship with career success and well-being, we wanted to establish that the NWO factors are distinct but related constructs. The three-factor structure of NWO has previously been confirmed based on the English version of the measure (Hall et al., 2013). To replicate these findings for the German-language version, confirmatory factor analysis (CFA) was applied, where we tested a factor model with three factors using the complete sample at T1 $(N=726)$. Mplus and the robust maximum likelihood estimation method (MLR) were used. Several model fit indices were examined: (1) the Satorra-Bentler corrected $\chi^{2}\left(\mathrm{SB}-\chi^{2}\right)$ test, (2) the comparative fit index (CFI), (3) the root mean square error of approximation (RMSEA), and (4) the standardized root mean square residual (SRMR). Very good model fit was obtained (SB- $\chi^{2}=194.34, d f=74, p<0.01$; $C F I=0.98 ; R M S E A=0.05,90 \% \mathrm{CI}=0.04-0.06 ; S R M R=0.04$ ). The standardized factor loadings ranged from 0.60 to 0.90 (all ps $<0.001$ ). The correlations between the three latent factors were all positive and ranged from 0.24 to 0.38 . Next, this three- 
factor model was compared with a single-factor model and three two-factor models in which different NWO facets were combined into one factor. The three-factor model displayed significantly better model fit than did all the other models (all ps $<0.001$ ), supporting the assumption that the three NWOs are clearly distinct but related constructs. We also applied CFA to assess the complete measurement model containing the three NWOs at T1 and the two indicators of career success plus life satisfaction at T2 among the longitudinal sample $(N=548)$, with all variables except salary specified as latent variables and indicated by their scale items. Again, very good model fit was obtained (SB- $\chi^{2}=426.33$, $d f=261, p<0.01 ; C F I=0.98$; $R M S E A=0.03$, $90 \% \mathrm{CI}=0.03-0.04 ; S R M R=0.04$ ). The standardized factor loadings ranged from 0.63 to 0.94 for all measures (all $p<0.001$ ).

\subsubsection{Consideration of control variables}

We considered several potentially relevant control variables, including status of having children, relationship status, contractual working hours, highest completed educational level, and organizational tenure. Previous empirical results, including those from meta-analyses, have shown that relationship status, educational level, and organizational tenure are significantly related to salary because they represent either forms of human capital or socio-economic hurdles (Ng \& Feldman, 2014a; Ng et al., 2005). Relationship status and hours worked are generally linked to work-family conflict because they represent role demands and resources that affect the intersection of work and family (Byron, 2005). Moreover, being married and having a higher educational level are generally related to higher subjective well-being, possibly because they provide emotional and material resources that increase well-being (Diener, Suh, Lucas, \& Smith, 1999). Because it is reasonable to assume that these variables are also related to NWO, they might represent an alternative explanation for any relationship found between NWO and the outcomes investigated in this paper. Bivariate correlations among the final longitudinal sample (Table 1) showed that the status of having children and relationship status were positively correlated with family orientation and community service orientation. Relationship status correlated positively with family and community orientation as well as all three outcome measures. Contractual working hours was not related to NWOs but to all three outcome measures positively. Educational level was positively related to salary but none of the NWOs. Organizational tenure was positively related to family orientation and all three outcomes. Hence, among the considered control variables, relationship status and organizational tenure were significantly related to NWOs and some outcome variables. However, hypothesis tests yielded identical results regardless of whether control variables were included. We therefore report the results without control variables to maximize power and offer more interpretable results (Bernerth \& Aguinis, 2016).

\subsection{NWO, career success, and life satisfaction}

As a first test of $\mathrm{H} 1 \mathrm{a}-\mathrm{H} 3 \mathrm{~b}$, the correlations between the manifest constructs were computed based on the responses to the NWO scales at T1 and the responses to the measures of career success and life satisfaction at T2 (Table 1). None of the NWO dimensions correlated with salary, providing support for neither the conflict nor the enrichment perspective and refuting H1a and H1b. Family orientation, but not the other NWO dimensions, showed a positive relationship with career satisfaction, thus partially confirming the enrichment perspective (H2b) while providing no support for the conflict perspective (H2a). The enrichment perspective received full support regarding life satisfaction (H3b) because all three nonwork orientations were positively related to life satisfaction, thus refuting H3a.

To further explore the unique effects of each NWO on career success and life satisfaction, we computed a Structural Equation Model (SEM) with the three NWOs at T1 as independent variables and the three outcome variables at T2 as dependent variables (Fig. 1). To account for the correlations between the NWO dimensions and between the outcome measures, the three NWOs at T1 and the three outcome measures at T2 were allowed to freely correlate within each measurement wave. The results largely supported bivariate correlation patterns. None of the NWO predicted salary. Family orientation was a significant predictor of career

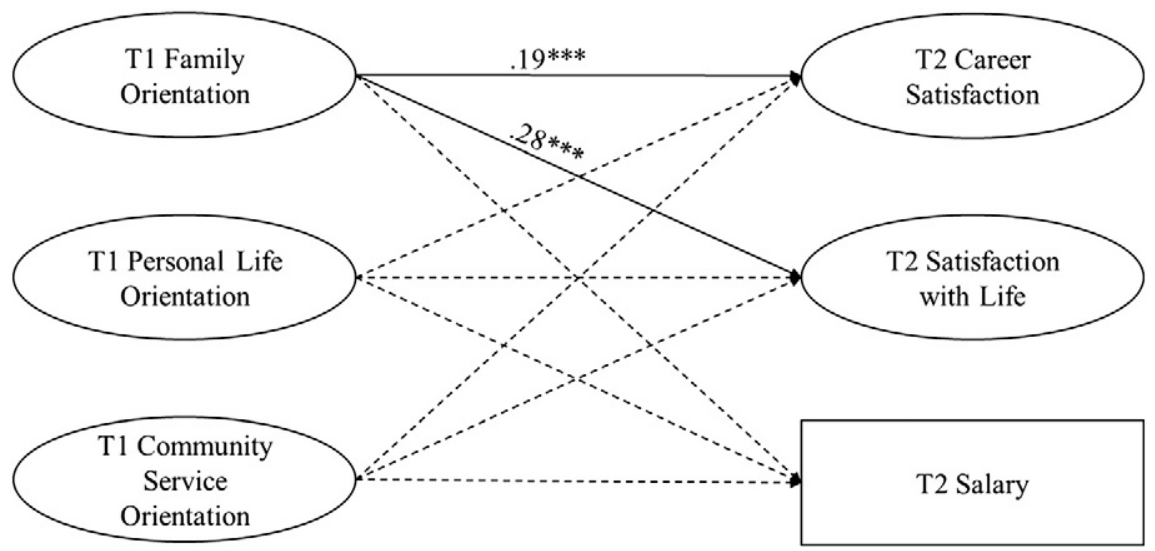

Fig. 1. Structural equation model of the three NWO at T1 predicting the three indicators of career success and well-being at T2 $(N=548)$. All variables except for salary were modeled as latent variables. Only significant standardized parameters are shown. For clarity, nonsignificant paths are shown as dotted lines, and the standardized parameters are not displayed. Correlations among the three NWOs and among the three dependent variables were allowed but are not shown. ${ }^{* * *} p<0.001$. 
satisfaction. The results also confirmed the impression from the correlation table that family orientation in particular was positively related to life satisfaction because when considering the shared variance with the other NWOs, only family orientation remained a significant predictor of life satisfaction. Combined, the three NWOs explained $<1 \%$ of the variance in salary (n.s.), $3 \%$ of the variance in career satisfaction $(p<0.001)$, and $8 \%$ of the variance in life satisfaction $(p<0.001)$.

\subsection{Exploring gender and age effects}

To address RQs 1 and 2 and to allow for meaningful group comparisons regarding NWO, we first established measurement invariance between gender and age groups (Sass, 2011; Vandenberg \& Lance, 2000). To examine the invariance of the three NWO dimensions, a sequence of nested CFA models with increasing invariance restrictions between males and females was tested (cf. Vandenberg \& Lance, 2000). For all three scales, measurement invariance was confirmed at each step of these model comparisons. This demonstrates that the same constructs are assessed for males and females and hence that the scales can be applied to compare NWO across gender. However, we only found a latent mean difference in personal life orientation, which was significantly lower for men than for women. There was no gender difference in family orientation and community-service orientation.

The comparison between age groups was conducted analogously to the procedure described for gender above. For communityservice orientation, complete equivalence was confirmed with the exception of one item uniqueness that had to be released. For personal life orientation, complete equivalence was confirmed with two exceptions: one item intercept and one item uniqueness had to be released. For family orientation, complete equivalence was confirmed with the exception of one item intercept that had to be released. Comparing means is considered meaningful even when only partial scalar invariance is established, as was the case for age in our sample (Steenkamp \& Baumgartner, 1998). However, there were no differences in mean levels between the age groups for any of the three NWO dimensions.

To address RQ 2, which pertained to potential moderator effects, we examined whether gender or age moderates the multiple regressions of the NWO scales with respect to the assessed outcomes. We used the multiple groups approach offered in SEM. For each outcome variable, with nested model comparisons, we investigated whether the regression coefficients were identical across gender and age groups. We did not find significant differences in model fit for the constrained versus unconstrained model for any of the regression models for either gender or age. We also ran model comparisons for the different combinations of gender and age (e.g., young women vs. young men) to explore interaction effects between gender and age. Because of the exploratory nature of these analyses, which resulted in 16 model comparisons, we applied a Bonferroni correction to reduce the likelihood that we obtained false-positive results. We did not find significant differences in model fit for any of these comparisons (complete results can be obtained from the authors upon request), which suggests that neither gender nor age moderates the relationship between NWO and the assessed outcomes.

\section{Discussion}

Although there is ample research concerning the work-family linkage, the broader investigation of career development from a whole-life perspective remains underdeveloped (Greenhaus \& Kossek, 2014). In the present study, we adopted the recently published new measurement scale of NWOs (Hall et al., 2013) into another language and established its factorial structure and measurement invariance across gender and age. Our study makes a contribution to the larger literature by examining whether and how concern for different nonwork roles relative to one's career are related to career success (i.e., salary and career satisfaction) and well-being (i.e., life satisfaction). We based our analysis on two different perspectives on the work-nonwork interface, namely, conflict and enrichment, in an attempt to test which perspective received more support. Moreover, we were also interested in exploring gender and age effects concerning NWOs.

\subsection{NWO as predictors of career success}

Based on a conflict perspective, it could be assumed that people with high NWO invest a considerable amount of their available resources in nonwork roles and that this would result in a lack of resources to meet work demands. This could in turn negatively affect their career progression and result in lower objective career success, as indicated by their salary level. However, our results did not support this conflict perspective and our results suggest that attaining objective career success does not suffer from considering nonwork domains. Meta-analyses showed that higher work involvement is positively related to job performance, salary, and promotions (Brown, 1996; Cooper-Hakim \& Viswesvaran, 2005; Lee et al., 2000; Ng \& Feldman, 2014a; Ng et al., 2005). However, NWOs are not necessarily an indicator of less work commitment (Hall et al., 2013), a proposition that is supported by the finding that NWOs were not related to working hours in our sample. Moreover, people can be simultaneously engaged in various life roles (Powell \& Greenhaus, 2010).

However, because NWOs were not related to salary, our results did also not confirm the enrichment perspective that would suggest that NWOs could lead to an accumulation of resources in nonwork domains that could then be used to improve salary-relevant performance and career advancement at work. The nonsignificant relationship between NWOs and salary in our study mirrors the contradictory results in other studies with more specific samples regarding how involvement in multiple roles is related to job performance (Graves et al., 2007; Ruderman et al., 2002; Weer et al., 2010). This suggests that occupational or organizational characteristics might moderate the relationship between NWOs and career success that should be investigated 
in future research. Possibly, managerial work-nonwork support and flexibility in working time and place might be critical in this regard because these organizational factors could make it easier for employees with strong NWOs to achieve career success.

Moreover, for future research, it would be interesting to more directly test enrichment and conflict processes linking NWOs and objective career success. Research showed that work-family conflict and enrichment can occur at the same time (Powell \& Greenhaus, 2006). Hence, it is possible that NWOs might have negative effects on work investment owing to resource depletion in some areas (e.g., time, energy) but that such negative effects are compensated for by positive effects that stem from increased environmental (e.g., family support) or personal (e.g., self-efficacy) resources that are accumulated in nonwork roles. Future research can more closely investigate such more specific mediating paths that link NWO with career success outcomes. In any case, our results provide new insights from a nonwork perspective on careers (Greenhaus \& Kossek, 2014) because they suggest that, overall, objective career success in terms of salary is not compromised when people consider nonwork roles when managing their careers.

Concerning subjective career success (i.e., career satisfaction), the conflict perspective would suggest that NWOs decreases career satisfaction because people are less likely to achieve subjectively valued career outcomes because of a lack of resources that can be invested in their career. By contrast, the enrichment perspective would predict that the positive spillover of affect and resources accumulated in nonwork roles increases career satisfaction. Although our study did not directly assess resource drain or spillover, our results provided more support for the enrichment perspective than for the conflict perspective. However, NWOs were only weakly related to career satisfaction, and only the relationship with family orientation proved statistically significant. On a general level, this result suggests that actively considering nonwork domains relative to one's career does not strongly affect the degree to which one feels satisfied with one's career. However, the moderate positive relationship between family orientation and career satisfaction is important from a work-home perspective on careers (Greenhaus \& Kossek, 2014) because the result implies that employees who consider family issues when managing their career report higher career satisfaction. This finding is in line with the result from Shockley et al. (2015) that having a satisfying personal life is a key dimension of subjective career success for many people. Moreover, other research suggests that subjective career success is higher for people who adopt a whole-life perspective on career development, possibly because they can better satisfy their various needs across life roles which leads to a more positive evaluation of their career (DiRenzo et al., 2015).

\subsection{NWOs as predictors of life satisfaction}

Apart from exploring the relationship between NWO and indicators of objective and subjective career success, the present study also investigated general well-being in terms of life satisfaction. Here, our results supported the enrichment perspective and the expansionist hypothesis, which suggest that being actively engaged in several life roles has a positive effect on wellbeing owing to an accumulation of resources in different life domains, cumulative effects on well-being stemming from different life roles, and the buffering effect of different life roles when faced with high demands in one specific role (Barnett, 2008; Greenhaus \& Powell, 2006). Interestingly, the strongest specific effect was observed with respect to family orientation, confirming the assumption that in addition to their work role, their family role is particularly salient for most people (Greenhaus \& Kossek, 2014); therefore, considering this role when managing one's career seems to have the greatest potential to positively affect overall life satisfaction. Together with the findings that family orientation was also the strongest predictor of career satisfaction, our results provide insights into a potentially differential functioning of the three NWOs. As our study suggests, family orientation seems to be the NWO with the most consistent positive linkage to satisfaction-related variables, both career-specific and more general. This reflects findings from Greenhaus, Collins, and Shaw (2003) who found that stronger investment in family relative to work is related to more reported quality of life. However, our study goes beyond previous studies that usually did not distinguish between different life roles when examining the linkages between nonwork roles and well-being (e.g., Graves et al., 2007; Ruderman et al., 2002). Although our study did not directly assess role investment, our results suggest that engagement in the family role, more so than personal life or community service, seems to have the greatest potential to increase well-being.

\subsection{NWO in relation to gender and age}

Finally, we explored gender and age differences concerning the prevalence of NWOs and explored whether these factors, or their interactions, might moderate the relationship between NWO and the assessed career and well-being outcomes. However, we observed no meaningful gender differences in NWO concerning family and community service. Previous research on role salience (Greer \& Egan, 2012) has also shown that women on average focus more on their home and family roles relative to their work roles than men. However, our study suggests that these findings do not translate into meaningful gender differences in the degree to which family considerations are taken into account when managing one's career. This finding may reflect changes in gender roles that have occurred over the last several decades in many societies (Sharabi, 2015), which also increasingly leads men to take an active role in the family. However, women scored higher in personal life orientation than men did in our study. It is possible that this finding reflects that women on average value their working roles less than their other life roles than men (Greenhaus \& Kossek, 2014). However, our study suggests that this might not translate into higher family orientation (in which men are equally strong - possibly because of changing societal norms), but instead, it may translate into higher personal life orientation. Finally, note that gender did not moderate the relationships between NWOs and the outcome measures, thus implying that gender does not affect the functioning of NWOs in relation to career success and well-being. This lack of an effect is 
important for a work-home perspective on careers (Greenhaus \& Kossek, 2014) because it suggests that there are neither genderspecific benefits nor gender-specific penalties when people consider nonwork domains when managing their careers.

Apart from gender, we also introduced age as a potentially critical variable to understand the functioning of NWO. However, we did not find significant age differences in now, nor did we find differences in younger or older persons' relationships between NWO and the investigated outcomes. These results suggest that in contrast to classical career stage theories that propose a disengagement from work in late careers (e.g., Super, 1990), older workers do not increasingly consider nonwork roles when compared with younger employees. These results also do not support the opposing assumption based on generational research (Lyons \& Kuron, 2014) that younger employees value nonwork roles more than older employees. In general, by exploring the moderating role of age, our study makes a contribution to the successful aging literature (Zacher, 2015). As our results suggest, NWOs do not seem to be a critical factor for successful aging at work because the effect of NWO on career and well-being outcomes does not change with age.

\subsection{Limitations and future research}

A limitation of our results is that we cannot make assertions about causality. The applied time-lagged design is useful to minimize shared method bias between predictor and outcome variables (Podsakoff et al., 2003). However, it is possible that the effects are inverted and that career and well-being outcomes affect the development of NWO rather than - or in addition to the effects examined in our study. Fully cross-lagged designs over longer periods of time or randomized (field) experiments will be needed to shed more light on the underlying causality of the relationships reported herein. Moreover, the investigated time-lag of six months might be too short to measure true causal effects emerging from NWOs on career and well-being outcomes, as these outcomes (specifically objective career success) might emerge from NWO only over several years. In this way, our study more closely reflects concurrent relationships between the assessed variables, and future research is needed to investigate the longer-term effects. In addition, although we used the conflict and enrichment perspectives to theorize about possible processes linking NWOs and outcomes, we did not directly assess conflict and enrichment processes as mediating variables. Future studies need to explore in more detail the proximal effects of NWOs on behaviors and experiences in different life domains, which might then lead to diverse work, career, and nonwork outcomes. Such research could also more directly investigate to what extent NWOs are linked to conflict and enrichment experiences between work and nonwork roles. Also, our study did not assess to what extent our participants spent time in various life roles (e.g., care activities) or were psychologically involved in different roles (e.g., role commitment). Moreover, apart from general life satisfaction, we did not assess outcomes in nonwork roles more specifically, such as family satisfaction. Future research on NWOs should consider assessing these variables. Finally, this study adopted a conflict and enrichment perspective to theorize about why NWOs might be related to career and well-being outcomes. However, other perspectives, such as how NWOs influence career decision-making could also fruitfully be applied by future studies to examine effects of NWOs.

Note that our study produced a series of nonsignificant findings and that the observed effects were mostly small. However, we believe that methodological flaws that can lead to null findings (such as the low reliability and/or validity of measures or small sample sizes) can be ruled out in the present case and that the nonsignificant findings are meaningful in increasing our understanding of nonwork issues in career development. One important issue is to replicate the (null) findings of the present study with different samples and in different cultural contexts. Another possible avenue for future research is to investigate moderators that might highlight the more specific conditions under which NWOs are related to career success and well-being. Going beyond the demographic variables examined herein, future studies could explore psychological variables such as occupational commitment or work centrality that might be present in different combinations with NWO and that might produce differential effects. In addition, research has shown that people have different preferences for integrating or segmenting work and nonwork roles and that integrating such roles can not only create more conflict but also engender possibilities of enrichment between life roles (Allen, Cho, \& Meier, 2014). It is thus feasible that personal preferences and environmental pressures for integration or segmentation of different life roles moderate the effects of NWO. Finally, it is possible that our focus on two clearly distinct age groups at the earlier and later end of working life has contributed to the weak effects because our study might have missed effects of NWOs that occur in mid-career, which might show particular salient family issues for many employees. Replicating our findings with mid-career employees would thus be instructive. In addition, we focused on individuals who were at least 50\% employed, possibly restricting the variance in NWOs because people with very high NWOs might choose to work even less, resulting in different relationships between NWOs and the assessed outcome variables among more heterogeneous samples.

\section{Conclusions and implications for practice}

To conclude, our study provides one of the first empirical inquiries into the potential consequences of when people consider different nonwork domains when managing their careers. Such knowledge is important to obtain a more complete understanding of contemporary careers that increasingly unfold at the intersection of work and nonwork life domains (Greenhaus \& Kossek, 2014). Our results suggest that NWOs might be particularly important for general life satisfaction and that this is true for both men and women and for younger and older employees. In addition, we found no indication across gender and age groups for the assumption that NWOs result in negative career or well-being consequences owing to resource depletion because of the focus on multiple life roles. Our study thus encourages individuals, leaders, and organizations to take a more whole-life 
perspective on career development and to depart from the assumption that career success can only be achieved by the "ideal worker" who is fully and almost exclusively devoted to his or her work (Dumas \& Sanchez-Burks, 2015).

For career counseling practice, our study suggests that career counselors should assess with qualitative (e.g., interviews) or quantitate methods (i.e., the herein used NWO scale) to what extent a client holds different NWOs. Counselors could then encourage clients to actively consider how their career decisions affect various important life domains and how their career planning is in turn affected by the concern that they have for other life roles. By integrating career and nonwork issues into career management and planning, career counselors can assist clients in taking a more whole-life perspective with respect to their careers. As our study suggests, the family role seems to merit special attention in this regard as considering work in relation to family concerns seems to have favorable consequences for their client's career and life satisfaction, regardless of gender or age.

\section{References}

Abele, A. E., \& Spurk, D. (2009). The longitudinal impact of self-efficacy and career goals on objective and subjective career success. Journal of Vocational Behavior, 74(1), 53-62. http://dx.doi.org/10.1016/j.jvb.2008.10.005.

Allen, T. D., \& Shockley, K. M. (2012). Older workers and work-family issues. In J. W., \& W. C. (Eds.), The Oxford handbook of work and aging (pp. 520-537). New York, NY, US: Oxford University Press.

Allen, T. D., Herst, D. E. L., Bruck, C. S., \& Sutton, M. (2000). Consequences associated with work-to-family conflict: A review and agenda for future research. Journal of Occupational Health Psychology, 5(2), 278-308

Allen, T. D., Cho, E., \& Meier, L. L. (2014). Work-family boundary dynamics. Annual Review of Organizational Psychology and Organizational Behavior, 1(1), 99-121. http://dx.doi.org/10.1146/annurev-orgpsych-031413-091330.

Amatea, E. S., Cross, E. G., Clark, J. E., \& Bobby, C. L. (1986). Assessing the work and family role expectations of career-oriented men and women - The lie role salience scales. Journal of Marriage and the Family, 48(4), 831-838. http://dx.doi.org/10.2307/352576.

Barnett, R. C. (2008). On multiple roles: Past, present, and future. In K., D. S., \& D. L. (Eds.), Handbook of work-family integration (pp. 75-93). San Diego: Academic Press.

Barnett, R. C., \& Hyde, J. S. (2001). Women, men, work, and family. American Psychologist, 56(10), 781-796.

Bernerth, J. B., \& Aguinis, H. (2015). A critical review and best-practice recommendations for control variable usage. Personnel Psychology, 69(1), 229-283. http://dx.doi. org/10.1111/peps.12103.

Brown, S. P. (1996). A meta-analysis and review of organizational research on job involvement. Psychological Bulletin, 120(2), 235-255. http://dx.doi.org/10.1037/ 0033-2909.120.2.235.

Byron, K. (2005). A meta-analytic review of work-family conflict and its antecedents. Journal of Vocational Behavior, 67(2), 169-198. http://dx.doi.org/10.1016/j.jvb. 2004.08.009.

Carstensen, L. L., Isaacowitz, D. M., \& Charles, S. T. (1999). Taking time seriously: A theory of socioemotional selectivity. American Psychologist, 54(3), 165-181. http:// dx.doi.org/10.1037/0003-066X.54.3.165.

Cooper-Hakim, A., \& Viswesvaran, C. (2005). The construct of work commitment: Testing an integrative framework. Psychological Bulletin, 131(2), 241-259. http://dx. doi.org/10.1037/0033-2909.131.2.241.

Diener, E., Emmons, R. A., Larsen, R. J., \& Griffin, S. (1985). The satisfaction with life scale. Journal of Personality Assessment, 49(1), 71-75. http://dx.doi.org/10.1207/ s15327752jpa4901_13.

Diener, E., Suh, E. M., Lucas, R. E., \& Smith, H. L. (1999). Subjective well-being: Three decades of progress. Psychological Bulletin, 125(2), 276-302. http://dx.doi.org/10. 1037/0033-2909.125.2.276.

DiRenzo, M. S., Greenhaus, J. H., \& Weer, C. H. (2015). Relationship between protean career orientation and work-life balance: A resource perspective. Journal of Organizational Behavior, 36(4), 538-560. http://dx.doi.org/10.1002/job.1996.

Dumas, T. L., \& Sanchez-Burks, J. (2015). The professional, the personal, and the ideal worker. The Academy of Management Annals, 9(1), 807-847. http://dx.doi.org/10. 1080/19416520.2015.1028810.

Erdogan, B., Bauer, T. N., Truxillo, D. M., \& Mansfield, L. R. (2012). Whistle while you work: A review of the life satisfaction literature. Journal of Management, 38(4), 1038-1083. http://dx.doi.org/10.1177/0149206311429379.

Gosling, S. D., Vazire, S., Srivastava, S., \& John, O. P. (2004). Should we trust web-based studies? A comparative analysis of six preconceptions about internet questionnaires. American Psychologist, 59(2), 93-104. http://dx.doi.org/10.1037/0003-066x.59.2.93.

Graves, L. M., Ohlott, P. J., \& Ruderman, M. N. (2007). Commitment to family roles: Effects on managers' attitudes and performance. Journal of Applied Psychology, 92(1), 44-56. http://dx.doi.org/10.1037/0021-9010.92.1.44.

Grawitch, M. J., Maloney, P. W., Barber, L. K., \& Mooshegian, S. E. (2013). Examining the nomological network of satisfaction with work-life balance. Journal of Occupational Health Psychology, 18(3), 276-284. http://dx.doi.org/10.1037/a0032754.

Greenhaus, J. H., \& Beutell, N. J. (1985). Sources of conflict between work and family roles. The Academy of Management Review, 10 (1), 76-88.

Greenhaus, J. H., \& Kossek, E. E. (2014). The contemporary career: A work-home perspective. Annual Review of Organizational Psychology and Organizational Behavior, 1(1), 361-388. http://dx.doi.org/10.1146/annurev-orgpsych-031413-091324.

Greenhaus, J. H., \& Powell, G. N. (2006). When work and family are allies: A theory of work-family enrichment. Academy of Management Review, 31(1), 72-92.

Greenhaus, J. H., Parasuraman, S., \& Wormley, W. M. (1990). Effects of race on organizational experiences, job performance evaluations, and career outcomes. Academy of Management Journal, 33(1), 64-86. http://dx.doi.org/10.2307/256352.

Greenhaus, J. H., Collins, K. M., \& Shaw, J. D. (2003). The relation between work-family balance and quality of life. Journal of Vocational Behavior, 63(3), 510-531. http:// dx.doi.org/10.1016/S0001-8791(02)00042-8.

Greer, T. W., \& Egan, T. M. (2012). Inspecting the hierarchy of life roles: A systematic review of role salience literature. Human Resource Development Review, 11(4), 463-499. http://dx.doi.org/10.1177/1534484312445322.

Hall, D. T., Kossek, E. E., Briscoe, J. P., Pichler, S., \& Lee, M. D. (2013). Nonwork orientations relative to career: A multidimensional measure. Journal of Vocational Behavior, 83(3), 539-550. http://dx.doi.org/10.1016/J.Jvb.2013.07.005.

van der Heijden, B. I., Schalk, R., \& van Veldhoven, M. J. (2008). Ageing and careers: European research on long-term career development and early retirement. Career Development International, 13, 85-94. http://dx.doi.org/10.1108/13620430810860512.

Hobfoll, S. E. (1989). Conservation of resources: A new attempt at conceptualizing stress. American Psychologist, 44(3), 513-524

Judge, T. A., Livingston, B. A., \& Hurst, C. (2012). Do nice guys-and gals-really finish last? The joint effects of sex and agreeableness on income. Journal of Personality and Social Psychology, 102(2), 390-407. http://dx.doi.org/10.1037/a0026021.

Kaplan, S., Bradley, J. C., Luchman, J. N., \& Haynes, D. (2009). On the role of positive and negative affectivity in job performance: A meta-analytic investigation. Journal of Applied Psychology, 94(1), 162-176. http://dx.doi.org/10.1037/a0013115.

Katz, D., \& Kahn, R. L. (1978). The social psychology of organizations (2d ed.). New York: Wiley.

Kirchmeyer, C. (1992). Nonwork participation and work attitudes: A test of scarcity vs. expansion models of personal resources. Human Relations, 45(8), 775-795. http://dx.doi.org/10.1177/001872679204500802.

Kooij, D. T., De Lange, A. H., Jansen, P. G., Kanfer, R., \& Dikkers, J. S. (2011). Age and work-related motives: Results of a meta-analysis. Journal of Organizational Behavior, 32(2), 197-225. http://dx.doi.org/10.1002/job.665.

Kossek, E. E., Ruderman, M. N., Braddy, P. W., \& Hannum, K. M. (2012). Work-nonwork boundary management profiles: A person-centered approach. Journal of Vocational Behavior, 81(1), 112-128. http://dx.doi.org/10.1016/j.jvb.2012.04.003. 
Lee, K., Carswell, J. J., \& Allen, N. J. (2000). A meta-analytic review of occupational commitment: Relations with person- and work-related variables. Journal of Applied Psychology, 85(5), 799-811.

Lent, R. W., \& Brown, S. D. (2013). Social cognitive model of career self-management: Toward a unifying view of adaptive career behavior across the life span. Journal of Counseling Psychology, 60(4), 557-568. http://dx.doi.org/10.1037/a0033446.

Lyons, S., \& Kuron, L. (2014). Generational differences in the workplace: A review of the evidence and directions for future research. Journal of Organizational Behavior, 35, 139-157. http://dx.doi.org/10.1002/job.1913.

Masuda, A. D., McNall, L. A., Allen, T. D., \& Nicklin, J. M. (2012). Examining the constructs of work-to-family enrichment and positive spillover. Journal of Vocational Behavior, 80(1), 197-210. http://dx.doi.org/10.1016/j.jvb.2011.06.002.

Meyer, J. P., Stanley, D. J., Herscovitch, L., \& Topolnytsky, L. (2002). Affective, continuance, and normative commitment to the organization: A meta-analysis of antecedents, correlates, and consequences. Journal of Vocational Behavior, 61(1), 20-52. http://dx.doi.org/10.1006/jvbe.2001.1842.

Michel, J. S., Kotrba, L. M., Mitchelson, J. K., Clark, M. A., \& Baltes, B. B. (2011). Antecedents of work-family conflict: A meta-analytic review. Journal of Organizational Behavior, 32(5), 689-725. http://dx.doi.org/10.1002/job.695.

Ng, T. W. H., \& Feldman, D. C. (2014a). A conservation of resources perspective on career hurdles and salary attainment. Journal of Vocational Behavior, 85(1), 156-168. http://dx.doi.org/10.1016/j.jvb.2014.05.008.

Ng, T. W. H., \& Feldman, D. C. (2014b). Subjective career success: A meta-analytic review. Journal of Vocational Behavior, 85(2), 169-179. http://dx.doi.org/10.1016/j. jvb.2014.06.001.

Ng, T. W. H., Eby, L. T., Sorensen, K. L., \& Feldman, D. C. (2005). Predictors of objective and subjective career success. A meta-analysis. Personnel Psychology, 58(2), 367-408. http://dx.doi.org/10.1111/j.1744-6570.2005.00515.x.

Pavot, W., \& Diener, E. (2008). The satisfaction with life scale and the emerging construct of life satisfaction. The Journal of Positive Psychology, 3(2), 137-152.

Peterson, C., Ruch, W., Beermann, U., Park, N., \& Seligman, M. E. (2007). Strengths of character, orientations to happiness, and life satisfaction. The Journal of Positive Psychology, 2(3), 149-156.

Podsakoff, P. M., MacKenzie, S. B., Lee, J., \& Podsakoff, N. P. (2003). Common method biases in behavioral research: A critical review of the literature and recommended remedies. Journal of Applied Psychology, 88(5), 879-903. http://dx.doi.org/10.1037/0021-9010.88.5.879.

Powell, G. N., \& Greenhaus, J. H. (2006). Is the opposite of positive negative?: Untangling the complex relationship between work-family enrichment and conflict. Career Development International, 11(7), 650-659. http://dx.doi.org/10.1108/13620430610713508.

Powell, G. N., \& Greenhaus, J. H. (2010). Sex, gender, and decisions at the family $\rightarrow$ work interface. Journal of Management, 36(4), 1011-1039. http://dx.doi.org/10. $1177 / 0149206309350774$

Rothbard, N. P. (2001). Enriching or depleting? The dynamics of engagement in work and family roles. Administrative Science Quarterly, 46(4), 655-684. http://dx.doi. org/10.2307/3094827.

Ruderman, M. N., Ohlott, P. J., Panzer, K., \& King, S. N. (2002). Benefits of multiple roles for managerial women. Academy of Management Journal, 45(2), 369-386. http:// dx.doi.org/10.2307/3069352.

Sass, D. A. (2011). Testing measurement invariance and comparing latent factor means within a confirmatory factor analysis framework. Journal of Psychoeducational Assessment, 29(4), 347-363. http://dx.doi.org/10.1177/0734282911406661.

Seibert, S. E., Crant, J. M., \& Kraimer, M. L. (1999). Proactive personality and career success. Journal of Applied Psychology, 84(3), 416-427. http://dx.doi.org/10.1037/ 0021-9010.84.3.416.

Sharabi, M. (2015). Life domain preferences among women and men in Israel: The effects of socio-economic variables. International Labour Review, 154(4), 519-536. http://dx.doi.org/10.1111/j.1564-913X.2014.00020.x

Sharabi, M., \& Harpaz, I. (2007). Changes in work centrality and other life areas in Israel. A longitudinal study. Journal of Human Values, 13(2), 95-106.

Shockley, K. M., Ureksoy, H., Rodopman, O. B., Poteat, L. F., \& Dullaghan, T. R. (2015). Development of a new scale to measure subjective career success: A mixedmethods study. Journal of Organizational Behavior, 37(1), 128-153. http://dx.doi.org/10.1002/job.2046.

Steenkamp, J. -B. E. M., \& Baumgartner, H. (1998). Assessing measurement invariance in cross-national consumer research. Journal of Consumer Research, 25(1), 78-90. http://dx.doi.org/10.1086/209528.

Super, D. E. (1990). A life-span, life-space approach to career development. In D., \& L. (Eds.), Career choice and development (pp. 197-262) (2nd ed.). San Francisco, CA: Jossey-Bass.

Ten Brummelhuis, L. L., \& Bakker, A. B. (2012). A resource perspective on the work-home interface: The work-home resources model. American Psychologist, 67(7), 545-556. http://dx.doi.org/10.1037/a0027974.

Toossi, M. (2012). Labor force projections to 2020: A more slowly growing workforce. Monthly Labor Review, $135,43$.

Twenge, J. M., Campbell, S. M., Hoffman, B. J., \& Lance, C. E. (2010). Generational differences in work values: Leisure and extrinsic values increasing, social and intrinsic values decreasing. Journal of Management, 36(5), 1117-1142. http://dx.doi.org/10.1177/0149206309352246.

Van der Heijden, B. I. J. M., de Lange, A. H., Demerouti, E., \& Van der Heijde, C. M. (2009). Age effects on the employability-career success relationship. Journal of Vocational Behavior, 74(2), 156-164. http://dx.doi.org/10.1016/J.Jvb.2008.12.009.

Vandenberg, R. J., \& Lance, C. E. (2000). A review and synthesis of the measurement invariance literature: Suggestions, practices, and recommendations for organizational research. Organizational Research Methods, 3(1), 4-70. http://dx.doi.org/10.1177/109442810031002.

van de Vijver, F. J., \& Leung, K. (1997). Methods and data analysis for cross-cultural research, vol. 1, Thousand Oaks, CA: Sage.

Wang, M., Olson, D. A., \& Shultz, K. S. (Eds.). (2013). Mid and late career issues: An integrative perspective. New York, NY: Routledge.

Weer, C. H., Greenhaus, J. H., \& Linnehan, F. (2010). Commitment to nonwork roles and job performance: Enrichment and conflict perspectives. Journal of Vocational Behavior, 76(2), 306-316. http://dx.doi.org/10.1016/j.jvb.2009.07.003.

Zacher, H. (2015). Successful aging at work. Work, Aging and Retirement, 1(1), 4-25. http://dx.doi.org/10.1093/workar/wau006.

Andreas Hirschi, PhD, is a full professor and the chair of the department of work and organizational psychology at the University of Bern, Switzerland. His major research interests are in the field of career development and career counseling and focus on calling, self-directed career management, subjective career success, and career orientations.

Anne Herrmann, PhD, is a Research Fellow at the University of Applied Sciences Switzerland. She earned her PhD at Leuphana University of Lueneburg, Germany. In her research, Anne utilizes the opportunities offered by latent variable modeling to address research question relevant for the world of work, specifically related to personality and career attitudes.

Noemi Nagy, MSc, is a doctoral candidate in work and organizational psychology at the University of Bern, Switzerland. Her research interests include the career development of older workers, personnel assessment, and leadership.

Daniel Spurk, PhD, is a senior researcher and lecturer for work and organizational psychology at the University of Bern, Switzerland. His major research interest is in career development and leadership. 